\title{
XXV. Experimental researches in electricity.-Seventh series
}

\section{Michael Faraday D.C.L. F.R.S.}

To cite this article: Michael Faraday D.C.L. F.R.S. (1834) XXV. Experimental researches in electricity.-Seventh series, Philosophical Magazine Series 3, 5:27, 161-181, DOI: 10.1080/14786443408649437

To link to this article: http://dx.doi.org/10.1080/14786443408649437

册 Published online: 01 Jun 2009.

Submit your article to this journal $[\pi$

山 Article views: 13

Q View related articles $\square$

4 Citing articles: 1 View citing articles ๘ 


\title{
LONDON AND EDINBURGH
}

\section{PHILOSOPHICAI، MAGAZINE}

A N D

\section{JOURNAL OF SCIENCE.}

\author{
[THIRD SERIES.]
}

$S E P T E M B E R \quad 1834$.

XXV. Experimental Researches in Electricity.-Seventh Series. By Michael Faraday, D.C.L. F.R.S. Fullerian Prof. Chem. Royal Institution, Corr. Memb. Royal and Imp. Acadd. of Sciences, Paris, Petersburgh, Florence, Copenhagen, Berlin, $\& c^{*} *$

§. 11. On Electro-chemical Decomposition, continued. I iv. On some general conditions of Electro-decomposition. I v. On a new Measurer of Volta-electricity. I vi. On the primitive or secondary character of bodies evolved in Electro-decomposition. I vii. On the definite nature and extent of Electro-chemical Decompositions. $\S .19$. On the absolute quantity of Electricity associated with the particles or atoms of Matter.

\section{Preliminary.}

661. THE theory which I believe to be a true expression of the facts of electro-chemical decomposition, and which I have therefore detailed in a former series of these Researchest, is so much at variance with those previously advanced, that I find the greatest difficulty in stating results, as I think, correctly, whilst limited to the use of terms which are current with a certain accepted meaning. Of this kind is the term pole, with its prefixes of positive and negative, and the attached ideas of attraction and repulsion. The general phraseology is that the positive pole attracts oxygen, acids,

* From the Philosophical Transactions for 1834, Part I. p. 77. This paper was received by the Royal Society January 9 th, and read January 23rd, February 6th and 13th, 1834.

+ A notice of the Researches here referred to has been given in the Lond. and Edinb. Phil. Mag. vol. iii. p. 460.-EDrt.

Third Series. Vol. 5. No. 27. Sept. 1834. 


\section{Dr. Faraday's Experimental Researches in Electricity.}

\&c., or more cautiously, that it determines their evolution upon the surface; and that the negative pole acts in an equal manner upon hydrogen, combustibles, metals, and bases. According to my view, the determining force is not at the poles, but woithin the decomposing body; and the oxygen and acids are rendered at the negative extremity of that body, whilst hydrogen, metals, \&c., are evolved at the positive extremity (518. 524.*).

662. To avoid, therefore, confusion and circumlocution, and for the sake of greater precision of expression than I can otherwise obtain, I have deliberately considered the subject with two friends, and with their assistance and concurrence in framing them, I purpose henceforward using certain other terms, which I will now define. The poles, as they are usually called, are only the doors or ways by which the electric current passes into and out of the decomposing body (556.); and they of course, when in contact with that body, are the limits of its extent in the direction of the current. The term has been generally applied to the metal surfaces in contact with the decomposing substance; but whether philosophers generally woullt also apply it to the surfaces of air (465.471.) and water (493.), against which $I$ have effected electro-chemical decomposition, is subject to doubt. In place of the term pole, I propose using that of Electrodet, and I mean thereby that substance, or rather surface, whether of air, water, metal, or any other body, which bounds the extent of the decomposing matter in the direction of the electric current.

663. The surfaces at which, according to the common phraseology, the electric current enters and leaves a decomposing body, are most important places of action, and require to be distinguished apart from the poles, with which they are mostly, and the electrodes, with which they are always, in contact. Wishing for a natural standard of electric direction to which I might refer these, expressive of their difference and at the same time free from all theory, I have thought it might be found in the earth. If the magnetism of the earth be due to electric currents passing round it, the latter must be in a constant direction, which, according to present usage of speech, would be from east to west, or, which will strengthen this help to the memory, that in which the sun appears to move. If in any case of electro-decomposition we consider the decomposing body as placed so that the current passing through it shall be in the same direction, and parallel to that supposed to exist in the earth, then the surfaces at which the

* These numbers, and others referred to in these Researches from 450. to 563., both inclusive, belong to the Fifth Series, noticed in our third volume, as already stated.-Enit.

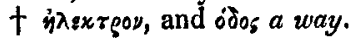


electricity is passing into and out of the substance would have an invariable reference, and exhibit constantly the same relations of powers. Upon this notion we purpose calling that towards the east the anode*, and that towards the west the cathodet; and whatever changes may take place in our views of the nature of electricity and electrical action, as they must affect the natural standard referred to in the same direction, and to an equal amount with any decomposing substances to which these terms may at any time be applied, there seems no reason to expect that they will lead to confusion, or tend in any way to support false views. 'The anode is therefore that surface at which the electric current, according to our present expression, enters: it is the negative extremity of the decomposing body; is where oxygen, chlorine, acids, \&c., are evolved; and is against or opposite the positive electrode. The cathode is that surface at which the current leaves the decomposing body, and is its positive extremity; the combustible bodies, metals, alkalies, and bases, are evolved there, and it is in contact with the negative electrode.

664. I shall have occasion in these Researches, also, to class bodies together according to certain relations derived from their electrical actions (822.); and wishing to express those relations without at the same time involving the expression of any hypothetical views, I intend using the following names and terms. Many bodies are decomposed directly by the electric current, their elements being set free; these I propose to call electrolytes $\neq$. Water, therefore, is an electrolyte. The bodies which, like nitric or sulphuric acids, are decomposed in a secondary manner (752.757.), are not included under this term. Then for electro-chemically decomposed, 1 shall often use the term electrolyzed, derived in the same way, and implying that the body spoken of is separated into its components under the influence of electricity: it is analogous in its sense and sound to analyze, which is derived in a similar manner. The term electrolytical will be understood at once. Muriatic acid is electrolytical, boracic acid is not.

665. Finally, I require a term to express those bodies which can pass to the electrodes, or, as they are usually called, the poles. Substances are frequently spoken of as being electronegative, or electro-positive, according as they go under the supposed influence of a direct attraction to the positive or negative pole. But these terms are much too significant for the use to which I should have to put them; for though the

* \&ya upwards, ódos a way; the way which the sun rises.

+ rata downwards, odos a way; the way which the sun sets.

$\ddagger \dot{\eta} \lambda \varepsilon x \tau \rho \circ$, and $\lambda v \omega$ solvo. N. Electrolyte, V. Electrolyze.

Y 2 


\section{Dr. Faraday's Experimental Researches in Electricity.}

meanings are perhaps right, they are only hypothetical, and may be wrong; and then, through a very imperceptible, but still very dangerous, because continual, influence, they do great injury to science, by contracting and limiting the habitual views of those engaged in pursuing it. I propose to distinguish these bodies by calling those anions* which go to the anode of the decomposing body; and those passing to the cathode, cationst; and when I have occasion to speak of these together, I shall call them ions. Thus, the chloride of lead is an electrolyte, and when electrolyzed evolves the two ions, chlorine and lead, the former being an anion, and the latter a cation.

666. These terms being once well defined, will, I hope, in their use enable me to avoid much periphrasis and ambiguity of expression. I do not mean to press them into service more frequently than will be required, for I am fully aware that names are one thing and science another $\neq$.

667. It will be well understood that $I$ am giving no opinion respecting the nature of the electric current now, beyond what I have done on a former occasion (283. $\$ 517$.$) ; and that$ though I speak of the current as proceeding from the parts which are positive to those which are negative (663.), it is merely in accordance with the conventional, though in some degree tacit, agreement entered into by scientific men, that they may have a constant, certain, and definite means of referring to the direction of the forces of that current.

II iv. On some general Conditions of Electro-chemical Decomposition.

669. From the period when electro-chemical decomposition was first effected to the present time, it has been a remark, that those elements which, in the ordinary phænomena of chemical affinity, were the most directly opposed to each other, and combined with the greatest attractive force, were those which were the most readily evolved at the opposite extremities of the decomposing bodies (549.).

670 . If this result was evident when water was supposed to be essential to, and was present, in almost every case of such decomposition (472.), it is far more evident now that it has been shown and proved that water is not necessarily con-

- évoo that which goes up. (Neuter participle.)

+ rxт⿺辶 that which goes doun.

\# Since this paper was read, I have changed some of the terms which were first proposed, that 1 might employ only such as were at the same time simple in their nature, clear in their reference, and free from hypothesis.

$\oint$ See Lond. and Edinb. Phil. Mag. vol. iii. p. 166.-Evir. 
cerned in the phænomena (474.), and that other bodies much surpass it in some of the effects supposed to be peculiar to that substance.

671. Water, from its constitution and the nature of its elements, and from its frequent presence in cases of electrolytic action, has hitherto stood foremost in this respect. Though a compound formed by very powerful affinity, it yields up its elements under the influence of a very feeble electric current; and it is doubtful whether a case of electrolyzation can occur, where, being present, it is not resolved into its first principles.

672. The various oxides, chlorides, iodides, and salts (402.), which I have shown are decomposable by the electric current when in the liquid state, under the same general law with water, illustrate in an equally striking manner the activity, in such decompositions, of elements directly and powerfully opposed to each other by their chemical relations.

673. On the other hand, bodies dependent on weak affnities very rarely give way. Take, for instance, glasses: many of those formed of silica, lime, alkali, and oxide of lead, may be considered as little more than solutions of substances one in another*. If bottle-glass be fused, and subjected to the voltaic pile, it does not appear to be at all decomposed (408.). If flint-glass, which contains substances more directly opposed, be operated upon, it suffers some decomposition; and if borate of lead glass, which is a definite chemical compound, be experimented with, it readily yields up its elements $\left(408 .^{*}\right)$.

674 . But the result which is found to be so striking in the instances quoted is not at all borne out by reference to other cases where a similar consequence might have been expected. It may be said, that my own theory of electro-chemical decomposition would lead to the expectation that all compound bodies should give way under the influence of the electric current with a facility proportionate to the strength of the affinity by which their elements, either proximate or ultimate, are combined. I am not sure that that follows as a consequence of the theory; but if the objection be supposed one presented by facts, I have no doubt it will be removed when we obtain a more intimate acquaintance with, and precise idea of, the nature of chemical affinity and the mode of action of an electric current over it (518.524.)): besides which, it is just as directly opposed to any other theory of electro-chemical

- Philosophical Transactions, 1830, p. 49.

t These numbers, and the others referred to from 380 . to 449 , both inclusive, belong to the Fourth Series of these Researches, noticed in Lond. and Edinb. Phil. Mag. vol. iii, p. 449,-Evit. 


\section{Dr. Faraday's Experimental Researches in Electricity.}

decomposition as the one I have propounded; for if it be admitted, as is generally the case, that the more directly bodies are opposed to each other in their attractive forces, the more powerfully do they combine, then the objection applies with equal force to any of the theories of electrolyzation which have been considered, and is an addition to those which I have taken against them.

675. Amongst powerful compounds which are not decomposed, boracic acid stands prominent (408.). Then again, the iodide of sulphur, and the chlorides of sulphur, phosphorus, and carbon, are not decomposable under common circumstances, though their elements are of a nature which would lead to a contrary expectation. Chloride of antimony (402. 690.), the hydro-carbons, acetic acid, ammonia, and many other bodies undecomposable by the voltaic pile, would seem to be formed by an affinity sufficiently strong to indicate that the elements were so far contrasted in their nature as to sanction the expectation that the pile would separate them, especially as in some cases of mere solution (530. 544.), where the affinity must by comparison be very weak, separation takes place*.

676. It must not be forgotten, however, that much of this difficulty, and perhaps the whole, may depend upon the absence of conducting power, which, preventing the transmission of the current, prevents of course the effects due to it. All known compounds being non-conductors when solid, but conductors when liquid, are decomposed, with perhaps the single exception at present known of periodide of mercury (679.691.); and even water itself, which so easily yields up its elements when the current passes, if rendered quite pure, scarcely suffers change, because it then becomes a very bad conductor.

677. If it should hereafter be proved that the want of decomposition in those cases where, from chemical considerations, it might be so strongly expected (669.674.672.), is due to the absence or deficiency of conducting power, it would also be proved, at the same time, that decomposition depends upon conduction, and not the latter upon the former (413.); and in water this seems to be very nearly decided. On the other hand, the conclusion is almost irresistible, that in electrolytes the power of transmitting the electricity across the substance is dependent upon their capability of suffering decomposition; taking place only whilst they are decomposing,

- With regard to solution, I have met with some reasons for supposing that it will probably disappear as a cause of transference, and intend resuming the consideration at a convenient opportunity. 
and being proportionate to the quantity of elements separated (821.). I may not, however, stop to discuss this point experimentally at present.

678. When a compound contains such elements as are known to pass towards the opposite extremities of the voltaic pile, still the proportions in which they are present appenr to be intimately connected with capability in the compound of suffering or resisting decomposition. Thus, the protochloride of tin readily conducts, and is decomposed (402.), but the perchloride neither conducts nor is decomposed (406.). The protiodide of tin is decomposed when fluid (402.); the periodide is not (405.). The periodide of mercury when fused is not decomposed (691.), even though it does conduct. I was unable to contrast it with the protiodide, the latter being converted into mercury and periodide by heat.

679. 'These important differences induced me to look more closely to certain binary compounds, with a view of ascertaining whether a lare regulating the decomposability according to some relation of the proportionals or equivalents of the elements, could be discovered. The proto compounds only, amongst those just referred to, were decomposable; and on referring to the substances quoted to illustrate the force and generality of the law of conduction and decomposition which I discovered (402.), it will be found that all the oxides, chlorides, and iodides subject to it, except the chloride of antimony and the periodide of mercury, (to which may now perhaps be added corrosive sublimate, ) are also decomposable, whilst many per compounds of the same elements, not subject to the law, were not so (405. 406.).

680. The substances which appeared to form the strongest exceptions to this general result were such bodies as the sulphuric, phosphoric, nitric, arsenic, and other acids.

681. On experimenting with sulphuric acid, I found no reason to believe that it was by itself a conductor of, or decomposable by, electricity, although I had previously been of that opinion (552.). When very strong it is a much worse conductor than if diluted*. If then subjected to the action of a powerful battery, oxygen appears at the anode, or positive electrode, although much is absorbed (728.), and hydrogen and sulphur appear at the cathode, or negative electrode. Now the hydrogen has with me always been pure, not sul. phuretted, and has been deficient in proportion to the sulphur present, so that it is evident that when decomposition occurred water must have been decomposed. I endeavoured to make the experiment with anhydrous sulphuric acid. It ap-

* De la Rive. 


\section{Dr. Faraday's Experimental Researches in Electricity.}

peared to me that in that state, when fused, sulphuric acid was not a conductor, nor decomposed; but I had not enough of the dry acid in my possession to allow me to decide the point satisfactorily. My belief is, that when sulphur appears by the action of the pile on sulphuric acid, it is the result of a secondary action, and that the acid itself is not electrolyzable (757.).

682. Phosphoric acid is, I believe, also in the same condition; but I have found it impossible to decide the point, because of the difficulty of operating on fused anhydrous phosphoric acid. Phosphoric acid which has once obtained water cannot be deprived of it by heat alone. When heated, the hydrated acid volatilizes. Upon subjecting phosphoric acid, fused upon the ring end of a wire (401.), to the action of the voltaic apparatus, it conducted, and was decomposed; but gas, which I believe to be hydrogen, was always evolved at the negative electrode, and the wire was not affected as would have happened had phosphorus been separated. Gas was also evolved at the positive electrode. From all the facts, I conclude it was the water and not the acid which was decomposed.

683. Arsenic Acid.-This substance conducted, and was decomposed; but it contained water, and I was unable at the time to press the investigation so as to ascertain whether a fusible anhydrous arsenic acid could be obtained. It forms, therefore, at present no exception to the general result.

684. Nitrous acid, obtained by distilling nitrate of lead, and keeping it in contact with strong sulphuric acid, was found to conduct and decompose slowly. But on examination there were strong reasons for believing that water was present, and that the decomposition and conduction depended upon it. I endeavoured to prepare a perfectly anhydrous portion, but could not spare the time required to procure an unexceptionable result.

685. Nitric acid is a substance which I believe is not decomposed directly by the electric current. As I want the facts in illustration of the distinction existing between primary and secondary deccmposition, I will merely refer to them in this place ( 752.$)$.

686. That these mineral acids should confer facility of conduction and decomposition on water, is no proof that they are competent to favour and suffer these actions in themselves. Boracic acid does the same thing, though not decomposable. M. De la Rive has pointed ont that chlorine has this power also; but being to us an elementary substance, it cannot be due to its capability of suffering decomposition.

687. Chloride of sulphur does not conduct, nor is it decom- 
posed. It consists of single proportionals of its elements, but is not on that account an exception to the rule (679.), which does not affirm that all compounds of single proportionals of elements are decomposable, but that such as are decomposable are so constituted.

688. Protochloride of phosphorus does not conduct nor become decomposed.

689. Protochloride of carbon does not conduct nor suffer decomposition. In association with this substance, I submitted the hydro-chloride of carbon from olefiant gas and chlorine to the action of the electric current; but it also refused to conduct or yield up its elements.

690. With regard to the exceptions (679.), upon closer examination, some of them disappear. Chloride of antimony (a compound of one proportional of antimony and one and a half of chlorine) of recent preparation was put into a tube (Plate I. fig. 13.) (789.), and submitted when fused to the action of the current, the positive electrode being of plumbago. No electricity passed, and no appearance of decomposition was visible at first; but when the positive and negative electrodes were brought very near each other in the chloride, then a feeble action occurred and a feeble current passed. The effect altogether was so small (although quite amenable to the law before given), and so unlike the decomposition and conduction occurring in all the other cases, that $I$ attribute it to the presence of a minute quantity of water, (for which this and many other chlorides have strong attractions, producing hydrated chlorides,) or perhaps of a true protochloride consisting of single proportionals (695. 796.).

691. Periodide of mercury being examined in the same manner, was found most distinctly to insulate whilst solid, but conduct when fluid, according to the law of liquido-conduction (402.); but there was no appearance of decomposition. No iodine appeared at the anode, nor mercury or other substance at the cathode. The case is, therefore, no exception to the rule, that only compounds of single proportionals are decomposable; but it is an exception, and I think the only one, to the statement, that all bodies subject to the law of liquido-conduction are decomposable. I incline, however, to believe, that a portion of protiodide of mercury is retained dissolved in the periodide, and that to its slow decomposition the feeble conducting power is due. Periodide would be formed, as a secondary result, at the anode; and the mercury at the cathode would also form, as a secondary result, protiodicle. Both these bodies would mingle with the fluid mass, and thus no final separation appear, notwithstanding the continued decomposition.

Third Series. Vol. 5. No. 27. Sept. 1834. 

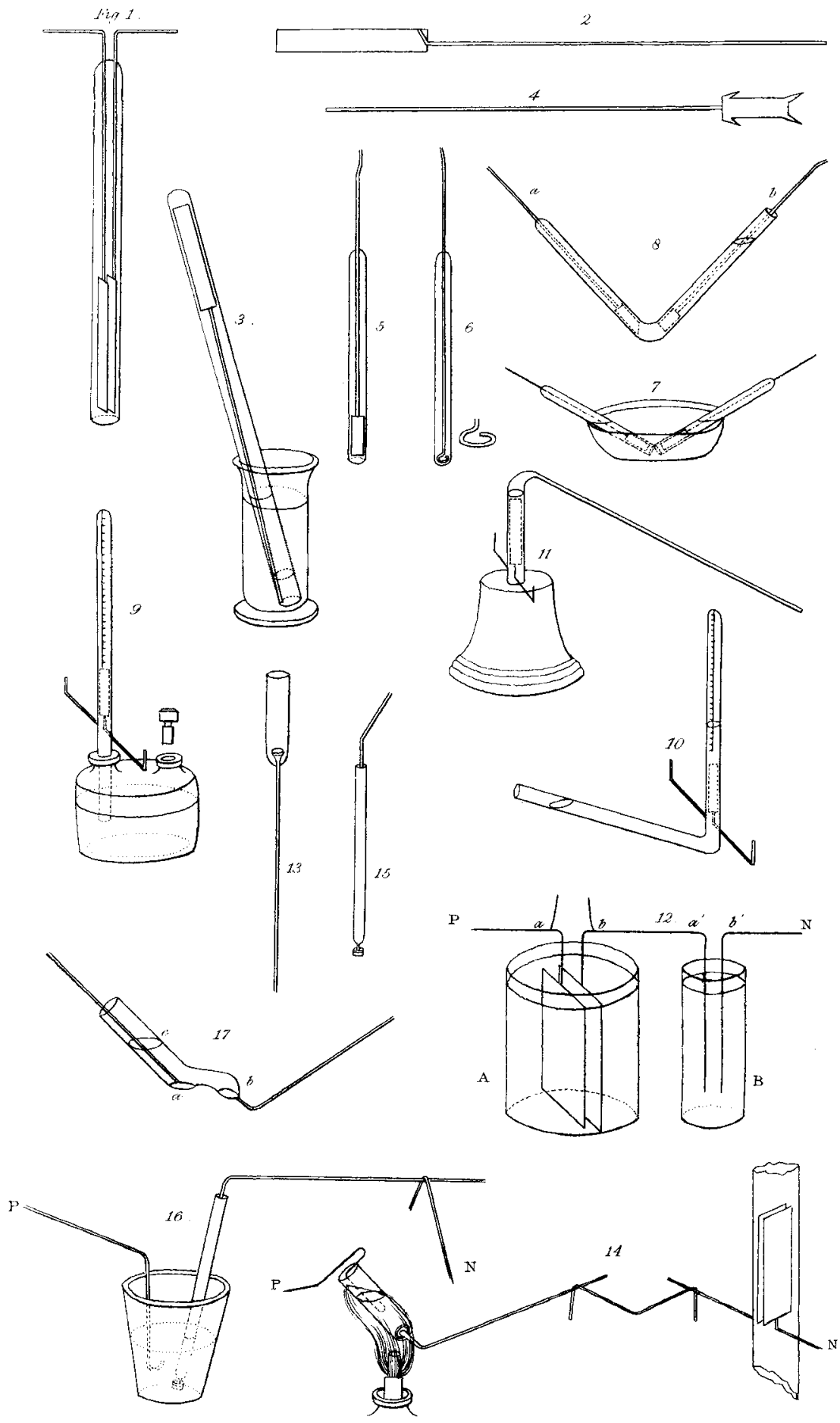
692. When perchloride of mercury was subjected to the voltaic current, it did not conduct in the solid state, but it did conduct when fluid. I think, also, that in the latter case it was decomposed; but there are many interfering circumstances which require examination before a positive conclusion can be drawn.

693. When the ordinary protoxide of antimony is subjected to the voltaic current in a fused state, it also is decomposed, although the effect from other causes soon ceases (102,801.). This oxide consists of one proportional of antimony and one and a half of oxygen, and is therefore an exception to the general law assumed. But in working with this oxide and the chloride, I observed facts which leaci me to doubt whether the compounds usually called the protoxide and the protochloride do not often contain other compounds, consisting of single proportions, which are the true proto compounds, and which, in the case of the oxide, might give rise to the decomposition above described.

694. The ordinary sulphuret of antimony is considered as being the compound with the smallest quantity of sulphur, and analogous in its proportions to the ordinary protoxide. But I find that if it be fused with metallic antimony, a new sulphuret is formed, containing much more of the metal than the former, and separating distinctly, when fused, both from the pure metal on the one hand, and the ordinary gray sulphuret on the other. In some rough experiments, the metal thus taken up by the ordinary sulphuret of antimony was equal to half the proportion of that previously in the sulphuret, in which case the new sulphuret would consist of single proportionals.

695. When this new sulphuret was dissolved in muriatic acid, although a little antimony separated, yet it appeared to me that a true protochloride, consisting of single proportionals, was formed, and from that, by alkalies, \&c., a true protoxide, consisting also of single proportionals was obtainable. But $\mathbf{l}$ could not stop to ascertain this matter strictly by analysis.

696. I helieve, however, that there is such an oxide; that it is often present in variable proportions in what is commonly called protoxide, throwing uncertainty upon the results of its analysis, and causing the electrolytic decomposition above described.

697. Upon the whole, it appears probable that all those binary compounds of elementary bodies which are capable of being electrolyzed when fluid, but not whilst solid, according to the law of liquido-conduction (394.), consist of single proportionals of their elementary principles; and it may be be- 
canse of their departure fiom this simplicity of composition, that boracic acid, ammonia, perchlorides, periodides, and many other direct compounds of elements, are indecomposable.

698. With regard to salts and combinations of compound bodies, the same simple relation does not appear to hold good. I could not decide this by bisulphates of the alkalies, for as long as the second proportion of acid remained, water was retained with it. The fused salt, therefore, conducted, and was decomposed; but hydrogen always appeared at the negative electrode.

699. A biphosphate of soda was prepared by heating, and ultimately fusing, the ammonia-phosphate of soda. In this case the fused bisalt conducted, and was decomposed; but a little gas appeared at the negative electrode, and though I believe the salt itself was electrolyzed, I am not quite satisfied that water was entirely absent.

700. Then a biborate of soda was prepared; and this, 1 think, is an unobjectionable case. 'The salt, when fused, conducted, and was decomposed, and gas appeared at both electrodes: even when the boracic acid was increased to three proportionals the same effect took place.

$70 \mathrm{~J}$. Hence this class of compound combinations does not seem to be subject to the same simple law as the former class of binary combinations. Whether we may find reason to consider them as mere solutions of the compound of single proportionals in the excess of acid, is a matter which, with some apparent exceptions occurring amongst the sulphurets, must be left for decision by future examination.

702. In any investigation of these points, great care must be taken to exclude water; for if present, secondary effects are so frequently produced as often seemingly to indicate an electro-decomposition of substances, when no true result of the kind has occurred (74.2. \&c.).

703. It is evident that all the cases in which decomposition does not occur may depend upon the want of conduction (677. 413.); but that does not at all lessen the interest excited by seeing the great difference of effect due to a change, not in the nature of the elements, but merely in their proportions, espe.cially in any attempt which may be made to elucidate and expound the beautiful theory put forth by Sir Humphry Davy*, and illustrated by Berzelius and other eminent philosophers, that ordinary chemical affinity is a mere result of the electrical attractions of the particles of matter.

* Philosophical Transactions, 1807, pp. 32, 39 ; also 1826, pp, 387, 389. [or Phil. Mag. first series, vol. xxviii. pp. 114, 220; also Phil. Mag. and Annals, N.S., vol, i. p. 31-199.-EdiT.] 


\section{I v. On a new Measurer of Volta-electricity.}

704. I have already said, when engaged in reducing common and voltaic electricity to one standard of measurement $\left(377^{*}\right)$, and again when introducing my theory of electro-chemical decomposition (504. 505. 510.), that the chemical decomposing action of a current is constant for a constant quantity of electricity, notwithstanding the greatest variations in its sources, in its intensity, in the size of the electrodes used, in the nature of the conductors (or non-conductors $(307 .+)$ ) through which it is passed, or in other circnmstances. The conclusive proofs of the truth of these statements shall be given almost immediately (783. \&c.).

705. I endeavoured upon this law to construct an instrument which should measure out the electricity passing through it, and which, being interposed in the course of the current used in any particular experiment, should serve at pleasure, either as a comparative standard of effect, or as a positive measurer of this subtile agent.

706. There is no substance better fitted, under ordinary circumstances, to be the indicating body in such an instrument than water; for it is decomposed with facility when rendered a better conductor by the addition of acids or salts; its elements may in numerous cases be obtained and collected without any embarrassment from secondary action, and, being gaseous, they are in the best physical condition for separation and measurement. Water, therefore, acidulated by sulphuric acid, is the substance I shall generally refer to, although it may become expedient in peculiar cases or forms of experiment to use other bodies (843.).

707. The first precaution needful in the construction of the instrument was to avoid the recombination of the evolved gases, an effect which the positive electrode has been found so capable of producing (571. $\ddagger$ ). For this purpose various forms of decomposing apparatus were used. The first consisted of straight tubes, each containing a plate and wire of platina soldered together by gold, and fixed hermetically in the glass at the closed extremity of the tube (Plate I. fig. 5.) The tubes were about eight inches long, 0.7 of an inch in diameter, and graduated. The platina plates were about an inch long, as wide as the tubes would permit, and adjusted as near

* See Lond. and Edinb. Phil. Mag., vol. iii. p. 362.-EnIr.

$\dagger$ Ibid. p. 171 .

I This and every other number referred to in these Researches, from 564 . to 660 ., belong to the Sixtb Series, noticed in Lond. and Edinb. Phil. Mag., vol. iv. p. 291.-Enrt. 
to the mouths of the tubes as was consistent with the safe collection of the gases evolved. In certain cases, where it was required to evolve the elements upon as small a surface as possible, the metallic extremity, instead of being a plate, consisted of the wire bent into the form of a ring (fig. 6.). When these tubes were used as measurers, they were filled with the dilute sulphuric acid, and inverted in a basin of the same liquid (fig. 7.), being placed in an inclined position, with their mouths near to each other, that as little decomposing matter should intervene as possible; and also, in such a direction that the platina plates should be in vertical planes (720.).

708. Another form of apparatus was that delineated (fig. 8.). The tube is bent in the middle; one end is closed; in that end is fixed a wire and plate, $a$, proceeding so far downwards, that, when in the position figured, it shall be as near to the angle as possible, consistently with the collection, at the closed extremity of the tube, of all the gas evolved against it. The plane of this plate is also perpendicular (720.). The other metallic termination, $b$, is introduced at the time decomposition is to be effected, being brought as near the angle as possible, without causing any gas to pass from it towards the closed end of the instrument. The gas evolved against it is allowed to escape.

709. The third form of apparatus contains both electrodes in the same tube; the transmission, therefore, of the electricity, and the consequent decomposition, is far more rapid than in the separate tubes. The resulting gas is the sum of the portions evolved at the two electrodes, and the instrument is better adapted than either of the former as a measurer of the quantity of voltaic electricity transmitted in ordinary cases It consists of a straight tube (fig. 9.) closed at the upper extremity, and graduated, through the sides of which pass the platina wires (being fused into the glass), which are connected with two plates within. The tube is fitted by grinding into one mouth of a double-necked bottle. If the latter be one half or two thirds full of the dilute sulphuric acid, it will, upon inclination of the whole, flow into the tube and fill it. When an electric current is passed through the instrument, the gases evolved against the plates collect in the upper portion of the tube, and are not subject to the recombining power of the platina.

710. Another form of the instrument is given at fig. 10 .

711. A fifth form is delineated (fig. 11.). This I have found exceedingly useful in experiments continued in succession for days together, and where large quantities of indicating gas were to be collected. It is fixed on a weighted foot, 


\section{Dr. Faraday's Experimental Researches in Electricity.}

and has the form of a small retort containing the two electrodes: the neck is narrow, and sufficiently long to deliver gas issuing from it into a jar placed in a small pneumatic trongh. The electrode chamber, sealed hermetically at the part held in the stand, is five inches in length, and 0.6 of an inch in diameter; the neck about nine inches in length, and 0.4 of an inch in diameter internally. The figure will fully indicate the construction.

712. It can hardly be requisite to remark, that in the arrangement of any of these forms of apparatus, they, and the wires commecting them with the substance, which is collaterally subjected to the action of the same electric current, should be so far insulated as to ensure a certainty that all the electricity which passes through the one shall also be transmitted through the other.

713. Next to the precaution of collecting the gases, if mingled, out of contact with the platinum, was the necessity of testing the law of a definite electrolytic action, upon water at least, under all varieties of condition; that, with a conviction of its certainty, might also be obtained a knowledge of those interfering circumstances which would require to be practically guarded against.

714. The first point investigated was the influence or indifference of extensive variations in the size of the electrodes, for which purpose instruments like those last described (709. 710. 711.) were used. One of these had plates 0.7 of an inch wide, and nearly four inches long; another had plates only 0.5 of an inch wide, and 0.8 of an inch long; a third had wires 0.02 of an inch in diameter, and three inches long; and a fourth similar wires only half an inch in length. Yet when these were filled with dilute sulphuric acid, and, being placed in succession, had one common current of electricity passed through them, very nearly the same quantity of gas was evolved in all. The difference was sometimes in favour of one, and sometimes on the side of another; but the general result was that the largest quantity of gases was evolved upon the smallersurface of the wires.

715. Experiments of a similar kind were made with the single-plate, straight tubes (707.), and also with the curved tubes (708.), with similar consequences; and when these, with the former tubes, were arranged together in various ways, the result, as to the equality of action of large and small metallic surfaces when delivering and receiving the same current of electricity, was constantly the same. As an illustration, the following numbers are given. An instrument with two wires evolved $74: 3$ volumes of mixed gases; another with plates 
73.25 volumes; whilst the sum of the oxygen and hydrogen in two separate tubes amounted to 73.65 volumes. In another experiment the volumes were $55 \cdot 3,55 \cdot 3$, and $54 \cdot 4$.

716. But it was observed in these experiments, that in single-plate tubes (707.) more hydrogen was evolved at the negative electrode than was proportionate to the oxygen at the positive electrode: and generally, also, more than was proportionate to the oxygen and hydrogen in a double-plate tube. Upon more minutely examining these effects, I was led to refer them, and also the differences between wires and plates (714.), to the solubility of the gases evolved, especially at the positive electrode.

717. When the positive and negative electrodes are equal in surface, the bubbles which rise from them in dilute sulphuric acid are always different in character. Those from the positive plate are exceedingly small, and separate instantly from every part of the surface of the metal, in consequence of its perfect cleanliness (633.); whilst in the liquid they give it a hazy appearance, from their number and minuteness; are easily carried down by currents; and therefore not only present far greater surface of contact with the liquid than larger bubbles would do, but are retained a much longer time in mixture with it. But the bubbles at the negative surface, though they constitute twice the volume of the gas at the positive electrode, are nevertheless very inferior in number. They do not rise so universally from every part of the surface, but seem to be evolved at different points; and though so much larger, they appear to cling to the metal, separating with difficulty from it, and when separated, instantly rising to the top of the liquid. If, therefore, oxygen and hydrogen had equal solubility in, or powers of combining with, water under similar circumstances, still under the present conditions the oxygen would be far the most liable to solution; but when to these is added its well-known power of forming a compound with water, it is no longer surprising that such a compound should be produced in small quantities at the positive electrode; and indeed the bleaching power which some philosophers have observed in a solution at this electrode, when chlorine and similar bodies have been carefully excluded, is probably due to the formation there, in this manner, of oxywater.

718. That more gas was collected from the wires than from the plates, I attribute to the circumstance, that as equal quantities were evolved in equal times, the bubbles at the wires having been more rapidly produced, in relation to any part of the surface, must have been much larger; have been there- 
176 Dr. Faraday's Experimental Researches in Electricity.

fore in contact with the fluid by a much smaller surface, and for a much shorter time than those at the plates; hence less solution and a greater collection.

719. There was also another effect produced, especially by the use of large electrodes, which was both a consequence and a proof of the solution of part of the gas evolved there. The collected gas, when examined, was found to contain small portions of nitrogen. This I attribute to the presence of air dissolved in the acid used for decomposition. It is a wellknown fact, that when bubbles of a gas but slightly soluble in water or solutions pass through them, the portion of this gas which is dissolved displaces a portion of that previously in union with the liquid: and so, in the decompositions under consideration, as the oxygen dissolves, it displaces a part of the air, or at least of the nitrogen, previously united to the acid; and this proceeds most extensively with large plates, because the gas evolved at them is in the most favourable condition for solution.

720. With the intention of avoiding this solubility of the gases as much as possible, $I$ arranged the decomposing plates in a vertical position (707. 708.), that the bubbles might quickly escape upwards, and that the downward currents in the fluid should not meet ascending currents of gas. This precaution I found to assist greatly in producing constant results, and especially in experiments to be hereafter referred to, in which other liquids than dilute sulphuric acid, as for instance solution of potash, were used.

721. The irregularities in the indications of the measurer proposed, arising from the solubility just referred to, are but small, and may be very nearly corrected by comparing the results of two or three experiments. They may also be almost entirely avoided by selecting that solution which is found to favour them in the least degree (728.); and still further by collecting the hydrogen only, and using that as the indicating gas; for being much less soluble than oxygen, being evolved with twice the rapidity and in larger bubbles (717.), it can be collected more perfectly and in greater purity.

722. From the foregoing and many other experiments, it results that variation in the size of the electrodes causes no variation in the chemical action of a given quantity of electricity upon water.

723. The next point in regard to which the principle of constant electro-chemical action was tested, was variation of intensity. In the first place, the preceding experiments were repeated, using batteries of an equal number of plates, strongly and weakly charged; but the results were alike. They were 
then repeated, using batteries sometimes containing forty, and at other times only five pairs of plates; but the results were still the same. Variations therefore in the intensity, caused by difference in the strength of charge, or in the number of alternations used, produced no difference as to the equal action of large and small electrodes.

724. Still these results did not prove that variation in the intensity of the current was not accompanied by a corresponding variation in the electro-chemical effects, since the actions at all the surfaces might have increased or diminished together. The deficiency in the evidence is, however, completely supplied by the former experiments on differentsized electrodes; for with variation in the size of these, a variation in the intensity must have occurred. The intensity of an electric current traversing conductors alike in their nature, quality, and length, is probably as the quantity of electricity passing through a given sectional area perpendicular to the current, divided by the time (360. note); and therefore when large plates were contrasted with wires separated by an equal length of the same decomposing conductor (714.), whilst one current of electricity passed through both arrangements, that electricity must have been in a very different state, as to tension, between the plates and between the wires; yet the chemical results were the same.

725. The difference in intensity, under the circumstances described, may be easily shown practically, by arranging two decomposing apparatus as in fig. 12, where the same fluid is subjected to the decomposing power of the same current of electricity, passing in the vessel A between large platina plates, and in the vessel $B$ between small wires. If a third decomposing apparatus, such as that delineated fig. 11. (711.), be connected with the wires at $a b$, fig. 12 , it will serve sufficiently well, by the degree of decomposition occurring in it, to indicate the relative state of the two plates as to intensity; and if it then be applied in the same way, as a test of the state of the wires at $a^{\prime} b^{\prime}$, it will, by the increase of decomposition within, show how much greater the intensity is there than at the former points. The connexions of $\mathrm{P}$ and $\mathrm{N}$ with the voltaic battery are of course to be continued during the whole time.

726. A third form of experiment in which difference of intensity was obtained, for the purpose of testing the principle of equal chemical action, was to arrange three volta-electrometers, so that after the electric current had passed through one, it should divide into two parts, which, after traversing each one of the remaining instruments, should reunite. The

Third Series. Vol. 5. No. 27. Sept. 1834.

$2 \mathrm{~A}$ 


\section{Dr. Faraday's Experimental Researches in Electricity.}

sum of the decomposition in the two latter vessels was always equal to the decomposition in the former vessel. But the intensity of the divided current could not be the same as that it had in its original state; and therefore variation of intensity has no influence on the results if the quantity of electricity remain the same. The experiment, in fact, resolves itself simply into an increase in the size of the electrodes (725.).

727. The third point, in respect to which the principle of equal electro-chemical action on water was tested, was variation of the strength of the solution used. In order to render the water a conductor, sulphuric acid had been added to it (707.); and it did not seem unlikely that this substance, with many others, might render the water more subject to decomposition, the electricity remaining the same in quantity. But such did not prove to be the case. Diluted sulphuric acid, of different strengths, was introduced into different decomposing apparatus, and submitted simultaneously to the action of the same electric current (714.). Slight differences occurred, as before, sometimes in one direction, sometimes in another; but the final result was, that exactly the same quantity of roater wos decomposed in all the solutions by the same quantity of electricity, though the sulphuric acid in some was seventyfold what it was in others. The strengths used were of specific gravity $1 \cdot 495$, and downwards.

728. When an acid having a specific gravity of about $1 \cdot 336$ was employed, the results were most unitorm, and the oxygen and hydrogen (716.) most constantly in the right proportion to each other. Such an acid gave more gas than one much weaker acted upon by the same current, apparently because it had less solvent power. If the acid were very strong, then a remarkable disappearance of oxygen took place; thus, one made by mixing two measures of strong oil of vitriol with one of water, gave forty-two volumes of hydrogen, but only twelve of oxygen. The hydrogen was very nearly the same with that evolved from acid of the specific gravity 1.232 . I have not yet had time to examine minutely the circumstances attending the disappearance of the oxygen in this case, but imagine it is due to the formation of oxywater, which Thénard has shown is favoured by the presence of acid.

729. Although not necessary for the practical use of the instrument I am describing, yet as connected with the important point of constant electro-chemical action upon water, I now investigated the effects produced by an electric current passing through aqueous solutions of acids, salts, and compounds, exceedingly different from each other in their nature, and found them to yield astonishingly uniform results. But 
many of them which are connected with a secondary action will be more usefully described hereafter (778.).

730. When solutions of caustic potassa or soda, or sulphate of magnesia, or sulphate of soda, were acted upon by the electric current, just as much oxygen and hydrogen was evolved from them as from the diluted sulphuric acid, with which they were compared. When a solution of ammonia, rendered a better conductor by sulphate of ammonia (554.), or a solution of subcarbonate of potassa was experimented with, the hydrogen evolved was in the same quantity as that set free from the diluted sulphuric acid with which they were compared. Hence changes in the nature of the solution do not alter the constancy of electrolytic action upon reater.

731. I have already said, respecting large and small electrodes, that change of order caused no change in the general effect (715.). The same was the case with different solutions, or with different intensities; and however the circumstances of an experiment might be varied, the results came forth exceedingly consistent, and proved that the electro-chemical action was still the same.

732. I consider the foregoing investigation as sufficient to prove the very extraordinary and important principle with respect to WaTEI, that when subjected to the infuence of the electric current, a quantity of it is decomposed exactly proportionate to the quantity of electricity rohich has passed, notwithstanding the thousand variations in the conditions and circumstances under which it may at the time be placed; and further, that when the interference of certain secondary effects $(742$. \&c.), together with the solution or recombination of the gas and the evolution of air, are guarded against, the products of the decomposition may be collected with such accuracy, as to afford a very excellent and valuable measurer of the electricity concerned in their evolution.

733. The forms of instrument which I have given, figg. 9, 10, 11. (709. 710. 711.), are probably those which will be found most useful, as they indicate the quantity of electricity by the largest volume of gases, and cause the least obstruction to the passage of the current. The fluid which my present experience leads me to prefer, is a solution of sulphuric acid of specific gravity about 1.336 , or from that to specific gravity 1.25 ; but it is very essential that there should be no organic substance, nor any vegetable acid, nor other body, which, by being liable to the action of the oxygen or hydrogen evolved at the electrodes (773. \&c.), shall diminish their quantity, or add other gases to them.

$$
2 \text { A } 2
$$




\section{Dr. Faraday's Experimental Researches in Electricity.}

734. In many cases when the instrument is used as a comparative standard, or even as a measurer, it may be desirable to collect the hydrogen only, as being less liable to absorption or disappearance in other ways than the oxygen; whilst at the same time its volume is so large, as to render it a good and sensible indicator. In such cases the first and second form of apparatus have been used, figg. 7, 8. (707. 708.). The indications obtained were very constant, the variations being much smaller than in those forms of apparatus collecting both gases; and they can also be procured when solutions are used in comparative experiments, which, yielding no oxygen or only secondary results of its action, can give no indications if the educts at both electrodes be collected. Such is the case when solutions of ammonia, muriatic acid, chlorides, iodides, acetates, or other vegetable salts, \&c., are employed.

735. In a few cases, as where solutions of metallic salts liable to reduction at the negative electrode are acted upon, the oxygen may be advantageously used as the measuring substance. This is the case, for instance, with sulphate of copper.

736. There are therefore two general forms of the instrument which I submit as a measurer of electricity. One, in which both the gases of the water decomposed are collected (709. 710. 711.); and the other, in which a single gas, as the hydrogen only, is used (707. 708.). When referred to as a comparative instrument, (a use I shall now make of it very extensively,) it will not often require particular precaution in the observation; but when used as an absolute measurer, it will be needful that the barometric pressure and the temperature be taken into account, and that the graduation of the instruments should be to one scale; the hundredths and smaller divisions of a cubical inch are quite fit for this purpose, and the hundredth may be very conveniently taken as indicating a DEGREE of electricity.

737. It can scarcely be needful to point out further than has been done how this instrument is to be used. It is to be introduced into the course of the electric current, the action of which is to be exerted anywhere else, and if $60^{\circ}$ or $70^{\circ}$ of electricity are to be measured out, either in one or several portions, the current, whether strong or weak, is to be continued until the gas in the tube occupies that number of divisions or hundredths of a cubical inch. Or if a quantity competent to produce a certain effect is to be measured, the effect is to be obtained, and then the indication read off. In exact experiments it is necessary to correct the volume of gas for 
The Rev. P. Keith on the Internal Structure of Plants. 181

changes in temperature and pressure, and especially for moisture*. For the latter object the volta-electrometer (fig. 11.) is most accurate, as its gas can be measured over water, whilst the others retain it over acid or saline solutions.

738. I have not hesitated to apply the term degree, in ana$\log y$ with the use made of it with respect to another most important imponderable agent, namely, heat; and as the definite expansion of air, water, mercury, \&c., is there made use of to measure heat, so the equally definite evolution of gases is here turned to a similar use for electricity.

739. The instrument offers the only actual measurer of voltaic electricity which we at present possess. For without being at all affected by variations in time or intensity, or alterations in the current itself, of any kind, or from any cause, or even of intermissions of action, it takes note with accuracy of the quantity of electricity which has passed through it, and reveals that quantity by inspection; I have therefore named it a Volta-electrometer.

740. Another mode of measuring volta-electricity may be adopted with advantage in many cases, dependent on the quantities of metals or other substances evolved either as primary or as secondary results; but I refrain from enlarging on this use of the products, until the principles on which their constancy depends have been fully established (791. 843.).

741 . By the aid of this instrument $I$ have been able to establish the definite character of electro-chemical action in its most general sense; and I am persuaded it will become of the utmost use in the extensions of the science which these views afford. I do not pretend to have made its detail perfect, but to have demonstrated the truth of the principle, and the utility of the application.

[To be continued.]

XXVI. On the Internal Structure of Plants. By the Rev. Patrick Keith, F.L.S.

[Continued from p. 121.]

Composite Organs.

The Epidermis. - THE epidermis of the vegetable, a term borrowed from the anatomy of animals, is the external envelope or integument of the plant, extending over its whole surface, and covering the root, stem, branches, leaves, flower, and fruit, with their appendages, the summit

* For a simple table of correction for moisture, I nuay take the liberty of referring to my Chemical Manipulation, edition of $1830, \mathrm{p} .376$. 